DOI 10.37882/2500-3682.2021.08.08

\title{
ОБРАЗ СЧАСТЬЯ В ОБЫДЕННОМ СОЗНАНИИ: АССОЦИАТИВНЫЙ ЭКСПЕРИМЕНТ
}

\section{THE IMAGE OF HAPPINESS IN EVERYDAY CONSCIOUSNESS: AN ASSOCIATIVE EXPERIMENT}

\section{Izotova}

Summary: This paper examines the concept of happiness in everyday consciousness. The specifics of happiness are considered. With the help of an associative experiment, the descriptors of happiness can be grouped into 5 categories: the subject of happiness, the object of happiness, the image of happiness, internal and external signs of happiness. 22 subcategories of the implicit structure of happiness were also identified.

Keywords: happiness, associative experiment, subject of happiness, object of happiness, image of happiness, internal signs of happiness, external signs of happiness.
4 асто определения счастья от лучших умов человечества довольно разнятся: от мирного и спокойного принятия мира со всем его многообразии, до динамичного переустройства через противостояние и страдания.

Далай-лама считал, что счастье - это не то, что мы получаем в готовом виде. Оно происходит из наших собственных действий [1]. Элеонора Рузвельт полагала, что счастье - это не цель, это побочный продукт [2]. Теодор Исаак Рубин рассуждал, что счастье не приходит от выполнения легкой работы. Это послевкусие от того удовлетворения, которое приходит после решения трудной задачи, которая требовала всего, на что вы способны.

И если задуматься о счастье, то возникают объективные вопросы. Что такое счастье? Какие критерии счастья? Существует ли счастье или это выдумка? Во времена Аристотеля, философы стремились осмыслить эти вопросы. Аристотель определял счастье, как деятельность души в полноте добродетели. Он утверждал, что как таковое понимание счастья на прямую зависит от того, кого мы спрашиваем. В связи с этим возникла важная идея о том, что счастье у всех разное. Он считал, что счастье - это высшее благо, доступное человеку, но в чем именно заключается благо возникают расхождения [3].

Есть и другое мнение, согласно которому счастливым является человек, который ощущает себя таковым. При
Изотова Ирина Юрьевна

Аспирант, Тихоокеанский государственный университет izo27@mail.ru

Аннотация: В данной работе исследуется понятие счастье в обыденном сознании. Рассматривается специфика счастья. С помощью ассоциативного эксперимента дескрипторы счастья можно сгруппировать в 5 категорий: субъект счастья, объект счастье, образ счастья, внутренние и внешние признаки счастья. Так же были выделены 22 подкатегории имплицитной структуры счастья.

Ключевые слова: счастье, ассоциативный эксперимент, субъект счастья, объект счастья, образ счастья, внутренние признаки счастья, внешние признаки счастья.

таком подходе под счастьем понимается некоторое эмоциональное состояние, возможное максимальное положительное переживание.

Показатель счастья по большей части зависит от общего склад личности, характера и темперамента и в большей степени вопрос субъективного взгляда. Психолог Урсула Штанудингер описывает парадокс субъективного благополучия, и считает, что люди могут быть счастливы независимо от наличия очевидных причин для этого [4].

Американские психологи Соня Любомирски и Кен Шелдон сформировали новую модель счастья, которая была основана на обширных исследованиях, и назвали ее «модель пирога». Данная модель состоит из 3 частей, и содержит разные факторы, с помощью которых люди оценивают уровень счастья или степень удовлетворенности своей жизни:

1. внешние факторы, которые не зависят от нас (место рождения, условия в которых мы живем и др.);

2. внутренние качества, связанны с устойчивым складом личности (эмоционально устойчивые и способны справляться со стрессом);

3. это то, что человек создает собственными руками (наши цели, отношения, которые мы выстраиваем с другими людьми).

В рамках исследования теоретической базы были рассмотрены различные формулы и модели счастья. Мы 
считаем, для изучения понимания счастья в обыденном сознании можно использовать ассоциативный эксперимент.

Применение ассоциативного эксперимента позволяет создавать экспериментальные ситуации, заключающиеся в предъявлении испытуемым различных заданий и вызывающие их вербальные реакции, имеющие неосознанный стереотипный характер, превратившиеся в «...навык, в стандарт восприятия и поведения».

Объектом исследования в ассоциативном эксперименте являются системы слов, а предметом - психологические закономерности их проявления. Ассоциативный эксперимент позволяет на основе формальной обработки данных сделать выводы относительно закономерностей «...семантического родства слов (или, вернее, субъективного переживания испытуемым степени их семантического родства)». Ассоциативная техника отражает как когнитивные структуры, стоящие за языковыми значениями, так и индивидуальные особенности испытуемых, их личностные смыслы. Последующая статистическая обработка устраняет влияние индивидуальных особенностей, выделяя аспекты, общие для всей группы испытуемых. Дополнительным преимуществом ассоциативного эксперимента является его простота, удобство применения, возможность работать с большой группой испытуемых одновременно, выделять некоторые неосознаваемые компоненты значения.

Таким образом, ассоциативный эксперимент позволяет получить ассоциативные нормы для изучаемого социального объекта, определить набор основных понятий, ставших его символами в сознании людей. На основании частотного и последующего логико-дедуктивного анализа выделяются смысловые блоки в восприятии объекта и реконструируется семантическое содержание образа в коллективном сознании. В итоге, исследуемый имидж объекта предстает как сложное образование, функционирующее в коллективном сознании как система образов и представлений, взаимосвязанных между собой.

Анализ материалов ассоциативных опытов позволяет не только установить состав семантических групп, входящих в семантическую систему тестируемого объекта, но и некоторые особенности их взаимосвязи. Это дает возможность сделать вывод об особенностях восприятия объекта в массовом сознании. Полученные слова-ассоциации и их классификация могут быть использованы для разработки инструментария на следующих этапах исследования.

Методы обработки информации: контент-анализ, математические методы статистической обработ- ки данных: среднее статистическое значение, количественная и качественная обработка, сравнительный и частотный анализ.

\section{Изучение имп^ицитной структуры конструкта «счастье»}

Для изучения имплицитной структуры представлений о счастье, был использован ассоциативный эксперимент. Данные методик позволили изучить психосемантическое пространство категории «счастье», а также определить категориальную структуру представлений о счастье.

Первым шагом нашего исследования стало проведение ассоциативного эксперимента. Всего в эксперименте участвовало 80 человек.

В качестве стимула в ассоциативном эксперименте были предъявлены понятия «счастье». Данные ассоциативного эксперимента были обработаны методом контент-анализа (Приложение). В качестве единиц анализа выступали слова ассоциации, которые были сгруппированы в основные категории анализа, такие как:

- субъект счастья;

- объект счастья;

- образ счастья;

- внутренние признаки счастья;

- внешние признаки счастья.

Общее количество ассоциаций составило - 939, в среднем по 12 от каждого респондента. Вклад категорий в пространство, отражающее их представления о счастье неоднороден (таблица 1).

Таблица 1.

Категориальное пространство, отражающее представление респондентов о счастье.

\begin{tabular}{|l|c|c|}
\hline \multicolumn{1}{|c|}{ Наименование категории } & кол-во ассоциаций & $\begin{array}{c}\text { \%вклад в массиве } \\
\text { ассоциаций }\end{array}$ \\
\hline субъект счастья & 151 & 16,1 \\
\hline объект счастья & 164 & 17,5 \\
\hline образ счастья & 240 & 25,6 \\
\hline внутренние признаки счастья & 268 & 28,5 \\
\hline внешние признаки счастья & 116 & 12,4 \\
\hline
\end{tabular}

Субъектом счастья являются те с кем респонденты ассоциируют данное понятие. Весь объем ассоциаций, входящий в данную категорию можно разбить на пять групп:

- люди, связанные семейным родством (дети, мама, муж, жена, дочь, сестра, родители, семья);

- люди, не имеющие семейных связей, но находящиеся с испытуемым в близких, дружественных 
отношениях (близкие, свои люди, друзья);

- люди, не входящие в близкое окружение респондента (приятные люди, интересные люди, незнакомцы);

- домашние питомцы (животные, кошка, кролик, попугай, собака);

- объективированная сверхъестественная сущность (Бог).

Объектом счастья является то с чем респонденты ас- социируют данное понятие. В объектах счастья можно выделить подкатегории:

- природные объекты (море, природа, солнце, радуга, цветы, закат, водопад, воздух, дождь и др.);

- продукты питания (вкусная еда, мороженное, кофе, сладкое, мороженное и др.);

- недвижимость (дом, крыша над головой и т.д.);

- социальные объекты (деньги, машина, архитектура, парфюм, подарки, праздник и др.).

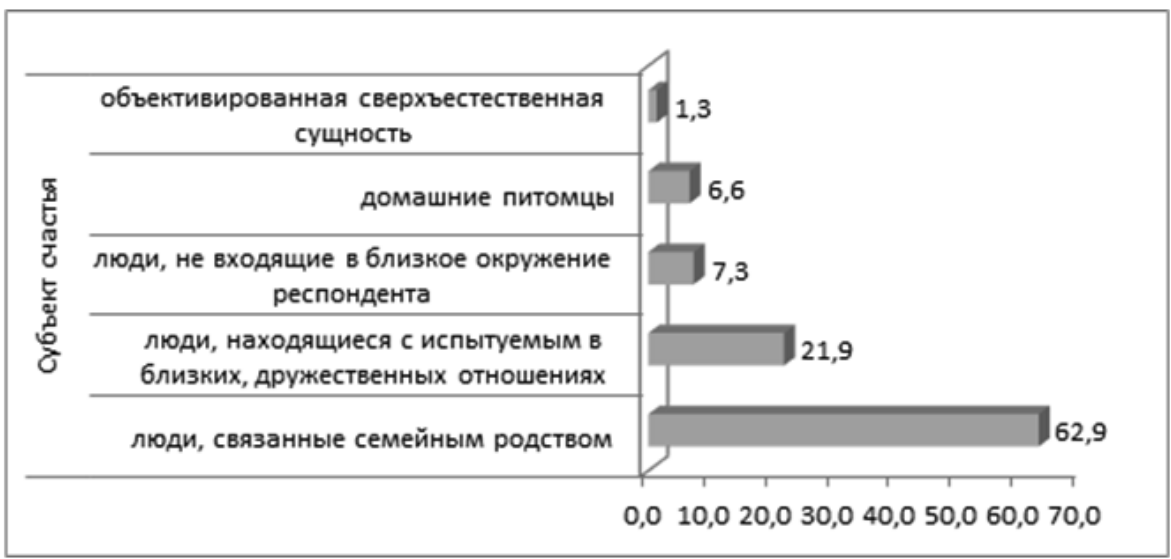

Рис. 1. Группа «субъект счастья» ассоциации респондентов.

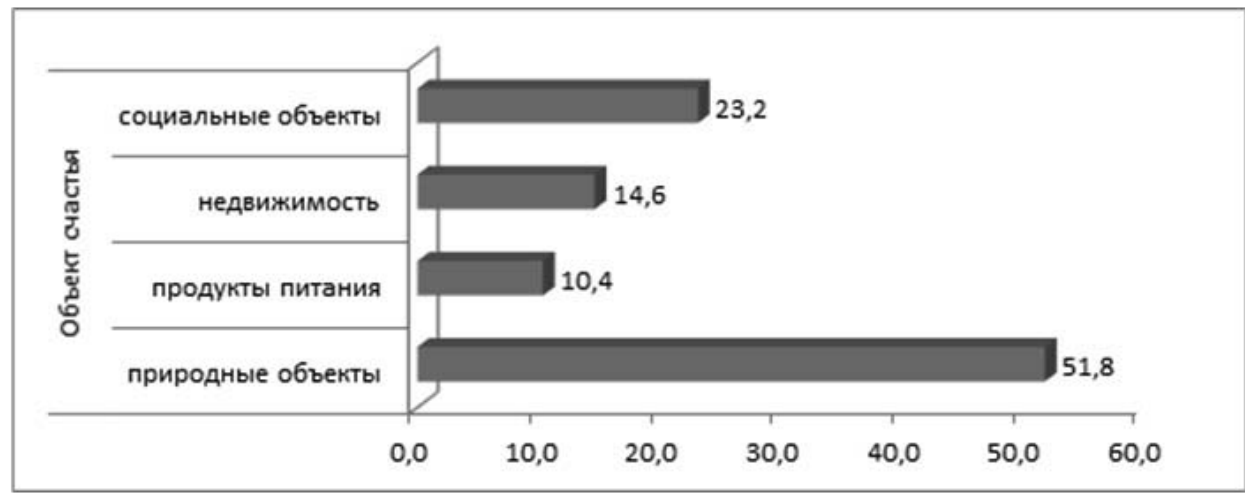

Рис. 2. Группа «объект счастья» ассоциации респондентов.

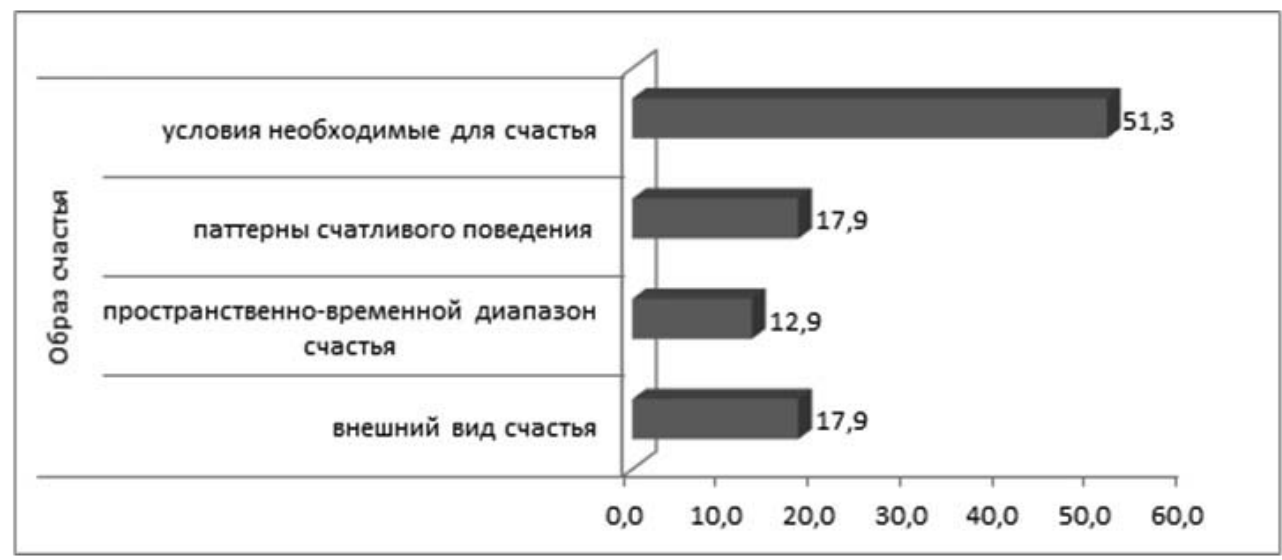

Рис. 3. Группа «образ счастья» ассоциации респондентов. 
Образ счастья включает представления о том какое оно, где его можно достичь, а также паттерны счастливого поведения:

- внешний вид счастья - белое, зеленое, прозрачное, ветер в волосах, сияние глаз, объятия, держать за руку, поцелуй, улыбка, смех и др.;

- пространственно-временной диапазон счастья (детство, молодость, прошлое, жизнь без иллюзий и ожиданий, утро, день, лето, осень, Париж);

- паттерны счастливого поведения (интересная работа, путешествие, отдых, отпуск, секс, хобби, танцы, творчество и др.);

- условия необходимые для счастья (здоровье, здоровье близких, духовность, возможность чувственного познания).

К внешним признакам счастья респонденты относят:

- внешнее благополучие (благополучие, признание, безопасность, благодарность, защита, взаимопонимание, поддержка и др.);

- забота (уважение, делиться, возможности, идеи которые сбылись, открытость, создание, терпение и др.);

- изобилие (иметь, достаток, успех, достижение цели, открытие, осваивать, приумножение и др.);

- комфорт (тепло, тишина, красота, стабильность, мир, красивое тело, чистота и др.).

К внутренним признакам счастья респонденты относят:

- спокойствие (отсутствие переживаний, любовь к себе, гармония, наполненность, умиротворение, доверие, баланс с телом и мыслями);

- саморазвитие (знания, ресурсность, полезность, нужность, интерес, преодоление, созерцание и др.);

- радость (веселье, впечатления, удовольствие, легкость, полет, блаженство и др.);

- любовь (любить и быть любимым, слабость, чувства, эмоции, хорошее настроение и др.);

- свобода (уверенность, самодостаточность, ответственность, независимость, осознанность и др.).

Таким образом, сконструированная имплицитная структура конструкта «счастье» включает 5 категорий и 22 подкатегории (таблица 2).

Выводы: Таким образом в ходе эмпирического исследования мы обнаружили, что дескрипторы счастья можно сгруппировать в 5 категорий: субъект счастья, объект счастье, образ счастья, внутренние и внешние признаки счастья.

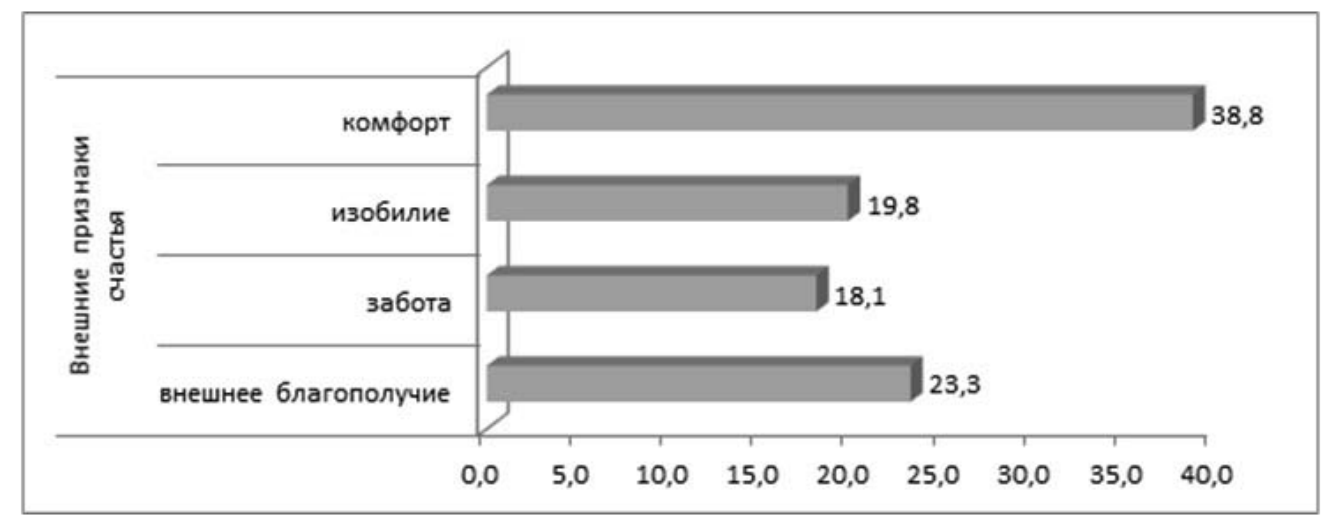

Рис. 4. Группа «внешние признаки счастья» ассоциации респондентов.

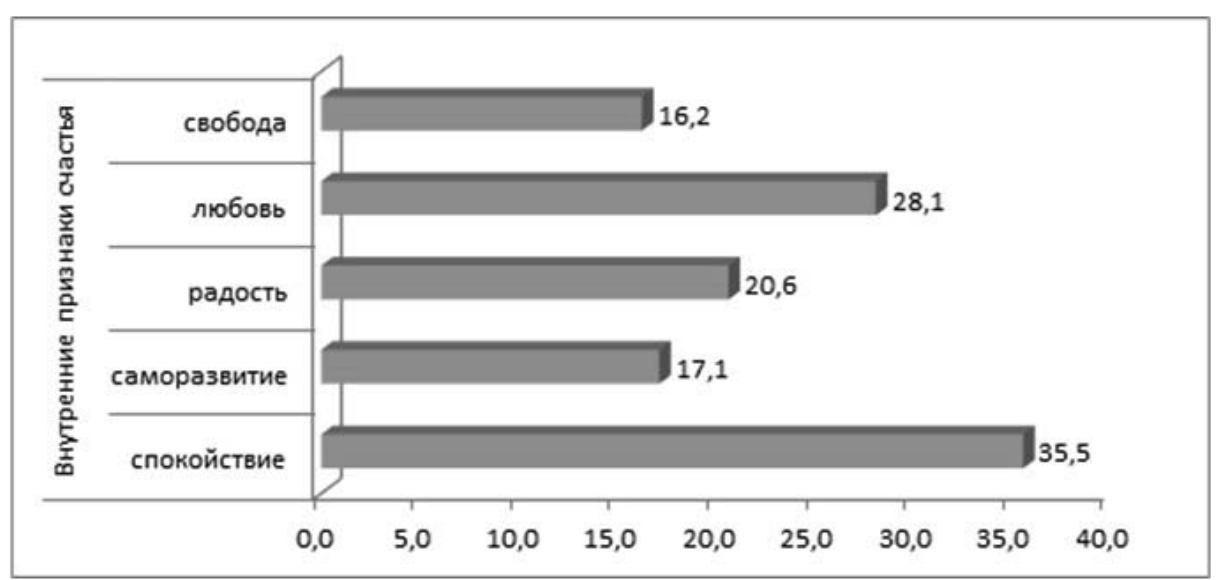

Рис. 5. Группа «внутренние признаки счастья» ассоциации респондентов. 
Таблица 2.

Имплицитная структура конструкта «счастье»

\begin{tabular}{|c|c|c|c|}
\hline Категория & Подкатегория & $\begin{array}{c}\text { Частота единиц анализа } \\
\text { подкатегорий }\end{array}$ & Влад подкатегорий \\
\hline \multirow[t]{5}{*}{ Субъект счастья } & люди, связанные семейным родством & 95 & 62,9 \\
\hline & $\begin{array}{l}\text { люди, не имеющие семейных связей, но находящиеся с } \\
\text { испытуемым в близких, дружественных отношениях }\end{array}$ & 33 & 21,9 \\
\hline & люди, не входящие в близкое окружение респондента & 11 & 7,3 \\
\hline & домашние питомцы & 10 & 6,6 \\
\hline & объективированная сверхъестественная сущность & 2 & 1,3 \\
\hline \multirow[t]{4}{*}{ Объект счастья } & природные объекты & 85 & 51,8 \\
\hline & продукты питания & 17 & 10,4 \\
\hline & недвижимость & 24 & 14,6 \\
\hline & социальные объекты & 38 & 23,2 \\
\hline \multirow[t]{4}{*}{ Образ счастья } & внешний вид счастья & 43 & 17,9 \\
\hline & пространственно-временной диапазон счастья & 31 & 12,9 \\
\hline & паттерны счастливого поведения & 43 & 17,9 \\
\hline & условия необходимые для счастья & 123 & 51,3 \\
\hline \multirow[t]{4}{*}{ Внешние признаки счастья } & внешнее благополучие & 27 & 23,3 \\
\hline & забота & 21 & 18,1 \\
\hline & изобилие & 23 & 19,8 \\
\hline & комфорт & 45 & 38,8 \\
\hline \multirow[t]{5}{*}{ Внутренние признаки счастья } & спокойствие & 81 & 35,5 \\
\hline & саморазвитие & 39 & 17,1 \\
\hline & радость & 47 & 20,6 \\
\hline & любовь & 64 & 28,1 \\
\hline & свобода & 37 & 16,2 \\
\hline
\end{tabular}

Категория «субъект счастья» включает в себя следующие подкатегории:

- люди, связанные семейным родством;

- люди, не имеющие семейных связей, но находящиеся с испытуемым в близких, дружественных отношениях;

- люди, не входящие в близкое окружение респондента;

- домашние питомцы;

- объективированная сверхъестественная сущность.

Категория «объект счастья» включает в себя следующие подкатегории:

- природные объекты;

- продукты питания;

- недвижимость;

- социальные объекты.

Категория «образ счастья» включает в себя следую- щие подкатегории :

- внешний вид;

- пространственно - временной диапазон счастья;

- условия необходимые для счастья;

- паттерны счастливого поведения.

Категория «внешние признаки счастья» включает в себя следующие подкатегории:

- внешние благополучие;

- забота;

- изобилие;

- комфорт.

Категория «внутренние признаки счастья» включает в себя следующие подкатегории:

- спокойствие;

- саморазвитие;

- радость;

- любовь;

- свобода. 


\section{ЛИТЕРАТУРА}

1. Нориюки У. Далай-лама о главном. М.: Издательский дом Ориенталия, 2014, С. 25

2. Roosevelt E. You Learn by Living. Harper \& Brothers Publishers, 1960., P. 95.

3. Аристотель. 0 душе. Рипол классик, 2018., С. 21-23,

4. Электронный ресурс https://nauchkor.ru/media/chto-takoe-schastie-57b4841e5f1be72d74516f52

5. Любомирски С. Психология счастья. Новый подход. СПб.: Издательский Дом Питер, 2014., стр. 89 — 95.

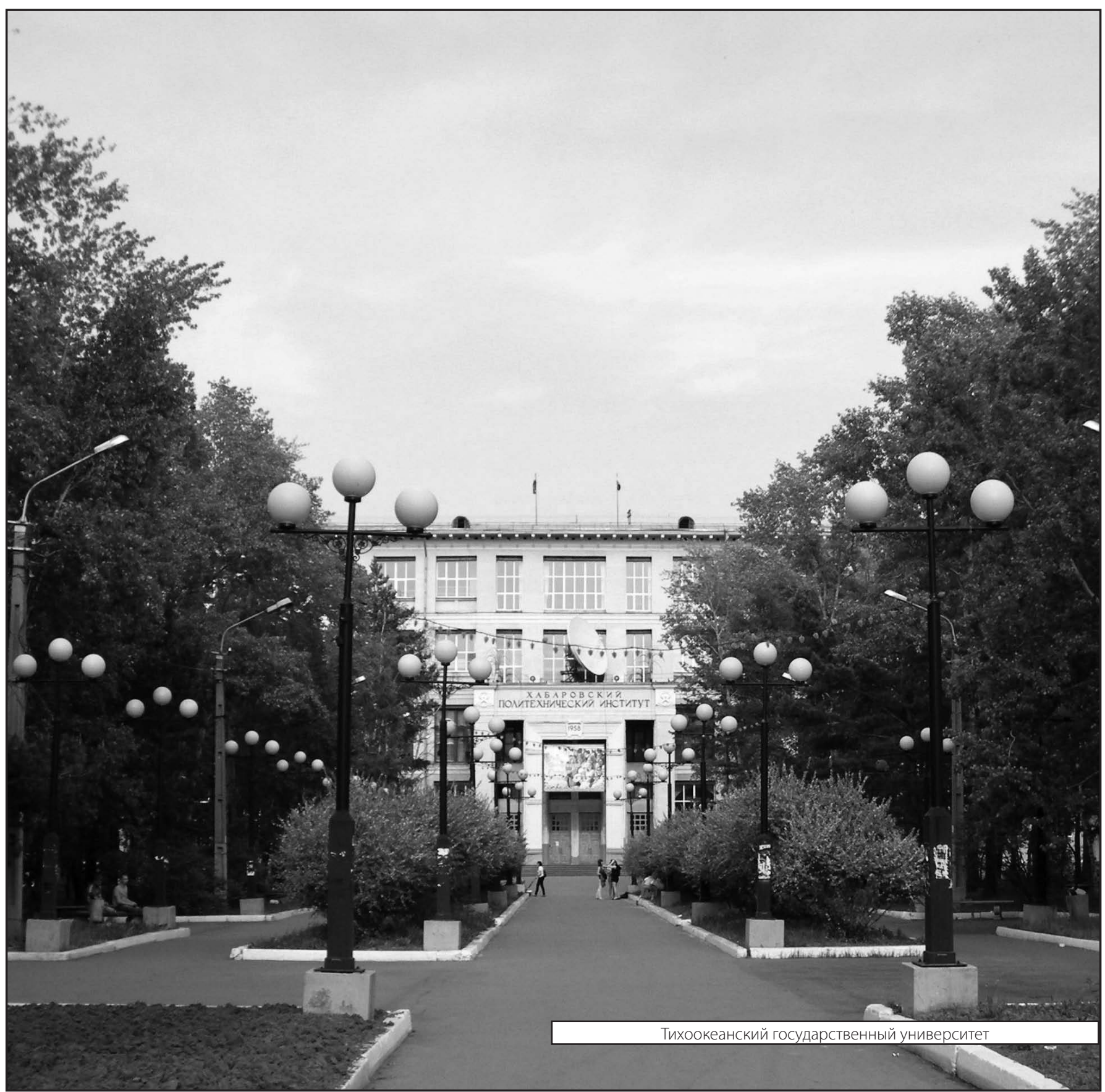

